\title{
Diode Laser Cyclophotocoagulation
}

\author{
Sushmita Kaushik, Surinder Singh Pandav, Parul Ichhpujani \\ Advanced Eye Centre, Postgraduate Institute of Medical Education and Research, Chandigarh, India
}

\section{INTRODUCTION}

Cyclodestructive procedures for intractable glaucoma unlikely to benefit from surgery, have evolved in the last seventy years from penetrating cyclodiathermy, ${ }^{1}$ cyclocryotherapy, ${ }^{2-4}$ ultrasound for ciliary body ablation ${ }^{5,6}$ and laser cyclophtotocoagulation. ${ }^{7-24}$ Destruction of the ciliary body to reduce the rate of aqueous production has been advocated in the treatment of glaucoma since the 1930 s, ${ }^{1}$ when penetrating cyclodiathermy was introduced. Cyclocryotherapy was initially shown to reduce intraocular pressure (IOP) by Beitti ${ }^{2}$ in 1950 , and was shown to be a reasonably safe and effective treatment that was less destructive and more predictable than cyclodiathermy. However, it did not gain popularity until 1960s when DeRoetth $^{3}$ reported a success rate of 73 percent with cyclocryotherapy. But problems did exist with cyclocryotherapy, e.g. severe postoperative pain, IOP rise, haemorrhage, marked inflammatory reaction, hypotony and severe visual loss. Ultrasound for ciliary ablation was briefly utilized, but it was abandoned because of marked scleral thinning and ectasia at the treatment site. ${ }^{5,6}$

The chief drawback of these procedures as a group, is a narrow therapeutic window, which implies that there is a very small safety zone in which it is effective without causing significant complications. Since Beckman's ${ }^{7}$ first report of transcleral cyclophotocoagulation using Ruby laser (693 nm), a wide variety of laser wavelengths have been used. The most frequently used lasers for this modality of treatment are the $1064 \mathrm{~nm} \mathrm{Nd}$ :Yag lasers ${ }^{8-11}$ and $810 \mathrm{~nm}$ semiconductor Diode. ${ }^{12-24}$ The energy uptake appears to be influenced by melanin absorption. ${ }^{10}$ Both wavelengths can produce thermal tissue damage, , and there is evidence that the semiconductor diode laser with $810 \mathrm{~nm}$ wavelength exhibits less scleral transmission and considerably greater absorption by melanin compared to the $1064 \mathrm{~nm}$ Nd:Yag laser. ${ }^{25}$ The clinically significant effect is that the energy needed to produce comparable lesions is less with the diode laser than that required with Nd:YAG laser. ${ }^{12}$ Due to the same reason, less laser energy has also been reported to be needed in pigmented eyes compared to produce the same effect. ${ }^{10,11}$
Though there are numerous reports describing the effectiveness of TSCPC, an accurate comparison of different techniques based on published studies is difficult because of the wide variation in treatment parameters and the lack of uniform definition of success. There are no standard treatment parameters defined, and the laser energy delivered varies considerably.

Currently, diode laser cyclophotocoagulation is the most widely used method of cyclodestruction. This article would review the indications, treatment protocols and reported results using this modality.

\section{INDICATIONS}

Cyclodestructive procedures, in their various forms, have been traditionally restricted to eyes with end-stage glaucoma which are some of the most difficult to control with conventional glaucoma filtration surgery. These are neovascular glaucoma, ${ }^{26}$ advanced developmental glaucoma, ${ }^{27}$ inflammatory glaucoma, ${ }^{28}$ glaucoma associated with corneal transplantation, ${ }^{29}$ silicone oil-induced glaucoma, ${ }^{30}$ and glaucoma in eyes with intractable chronic angle closure glaucoma. ${ }^{31}$ Cyclophotocoagulation is also used in eyes with limited visual potential, in urgent situations with dangerously elevated IOP, or for pain relief in eyes with no visual potential. ${ }^{32}$

\section{MECHANISM OF ACTION}

Diode laser transscleral cyclophotocoagulation is known to achieve its IOP-lowering effect via two independent mechanisms: by direct thermal destruction of the ciliary epithelial cells that produce aqueous, and by inducing inflammation that may in turn lead to decreased aqueous production and/or increased uveoscleral outflow. The former mechanism should produce relatively permanent IOP reduction, while the latter may result in transient IOP reduction that disappears as the inflammation clears. Experimental reports have described ciliary body atrophy with abnormal ciliary epithelium four weeks after cyclophotocoagulation. ${ }^{35}$ 


\section{HISTOPATHOLOGICAL CHANGES AFTER CYCLOPHOTOCOAGULATION}

In a study comparing the histologic appearance of transclerally and endoscopically treated human eye tissue, ${ }^{33}$ light microscopy revealed significant damage to the ciliary processes similar in morphologic appearance to those previously described. ${ }^{33-34}$ The laser-treated areas showed destruction of pigmented and non-pigmented ciliary epithelium and capillaries in the ciliary processes with pigment clumping, coagulative changes and destruction of the processes' stroma. Loss of the architectural organization appeared to extend into the ciliary muscle layer in some areas, while not in others.

In contrast, endoscopically-treated tissue revealed loss of the lacy appearance of the stroma of the ciliary processes with destruction of the nonpigmented epithelium and clumping of the pigmented epithelium with minimum to no coagulative changes of the tissue beyond the ciliary processes. Scanning electron microscopy demonstrated extensive shrinkage of the ciliary processes and effacement of the ciliary epithelium after treatment endoscopically, while transclerally treated tissue had extensive architectural disruption extending into the pars plana and iris stroma.

\section{SEMICONDUCTOR DIODE LASER}

A semiconductor solid state diode laser system (IRIS Oculight SLx, IRIS Medical Inc., Mountain View, CA) (Figure 1) with an $810 \mathrm{~nm}$ wavelength exhibits less scleral transmission ( 35\%) but considerably greater absorption by melanin than the 1064 nm Nd:YAG wavelength . The $810 \mathrm{~nm}$ semiconductor diode laser appears to offer a better method of cycloablation with potentially fewer complications as there is better absorption of this wavelength by the pigmented tissues of the ciliary body causing coagulation necrosis of the ciliary body stroma. ${ }^{8,9}$ Initial reports suggest a lower incidence of the complications with diode laser cyclophotocoagulation (DLCP) compared to that seen with other cyclodestructive techniques. ${ }^{10-12}$ These advantages, combined with the compact and portable nature of the diode, make it an attractive treatment modality.

An overall success rate between 35 percent and 85 percent has been reported with DLCP. ${ }^{13-21}$ However, risks and prognostic factors other than the type of glaucoma (e.g. age of patients) are yet to be determined.

The laser energy is delivered through a $600-\mu \mathrm{m}$ diameter quartz fiber with a flat, polished tip oriented by a handpiece (G-probe) designed to center treatment $1.2 \mu \mathrm{m}$ behind the surgical limbus with the fiber optic approximately parallel to the visual axis (Figure 2). Maximum power from the system is 3.0 watts for 9.9 seconds duration.

The probe handpiece footplate that comes in contact with the sclera is curved spherically to match the scleral contour. The anterior, curved edge of the footplate is designed to overlie

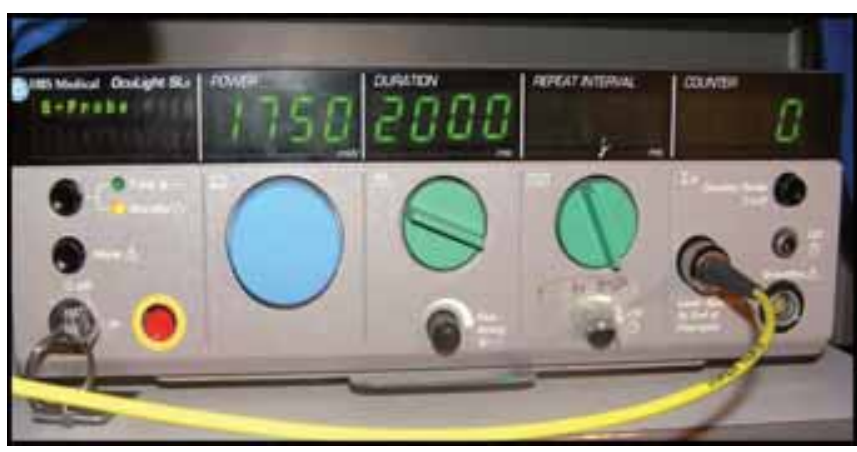

Fig. 1: Semiconductor solid state diode laser system (IRIS Oculight SLx, IRIS Medical Inc., Mountain View, CA)

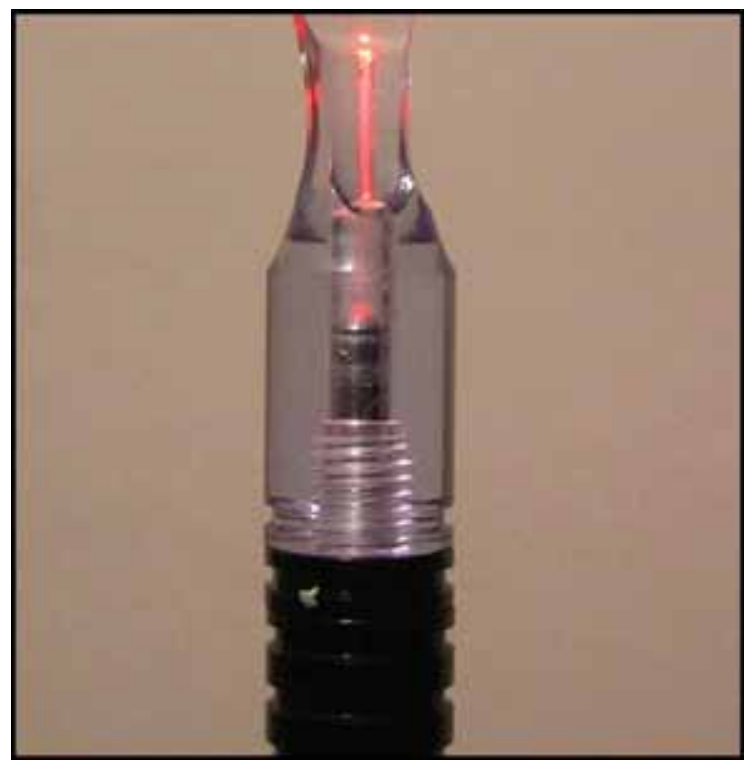

Fig. 2: IRIS G-probe (side view)

and match the surgical limbus during laser application. The probe handpiece has a fibre optic tip which protrudes $0.7 \mathrm{~mm}$ beyond the contact surface. The protruding fiberoptic indents the conjunctiva and the sclera to enhance laser light transmission.

Currently, the G-probe is sold as a single-use, disposable instrument. Despite its marketing as a single-use, disposable instrument, the IRIS diode laser G-probe has demonstrated reusability. ${ }^{35}$ To reuse the G-probe, care should be taken to minimize debris accumulation and tip damage by cleaning with alcohol wipes. However, anecdotal evidence points to some decrease in clinical effectiveness of the G-probe with reuse.

\section{TECHNIQUE}

A wavelength of $810 \mathrm{~nm}$ is particularly effective for energy transmission across the sclera and into the structures containing melanin pigment in the ciliary body epithelium and stroma. 
After taking an informed consent, local anaesthesia is given by peribulbar injection of lignocaine hydrochloride (2\%) in combination with bupivacaine hydrochloride (0.5\%). A lid speculum is used to separate the eyelids. The laser is set at an initial power of $1750 \mathrm{~mW}$, and a duration of 2 seconds. If there is no sound denoting tissue disruption (a "pop" or "snap" sound from within the eye), the power is titrated upwards till a "pop" is heard when the power is reduced by increments of $250 \mathrm{~mW}$ till no pop is heard. Each laser application is spaced approximately $2 \mathrm{~mm}$ apart, using half-width of the G-probe footplate as a guide, to produce burns in the ciliary processes. About 20 applications are required in $270^{\circ}$ (Figure 3). The superonasal quadrant is usually spared. Care is taken to apply the G-probe to the limbus indenting properly to ensure that the G-probe surface contour matches the scleral curvature and the posterior angulation is correctly oriented to protect the lens in phakic eyes from laser damage.

\section{POST-LASER TREATMENT}

Topical steroids and cycloplegics, along with oral analgesics, are prescribed as required. In patients on oral acetazolamide before laser treatment, it is continued for a period of 1 week after laser treatment also. At 1 week post-laser treatment oral acetazolamide can be discontinued if the IOP is $<22 \mathrm{~mm} \mathrm{Hg}$, with continuation of topical IOP lowering medications depending on the response. One can wait for a minimum of 4 weeks for the full IOP effect of the first DLCP to stabilize. After 4 weeks, if the IOP under medical treatment is persistently high on 2 consecutive visits separated by an interval of at least 1 week, a second session can be given in the same inferior $270^{\circ}$.

\section{EFFICACY OF DLCP}

Histopathologic studies comparing Nd: YAG laser to diode found that treatment with diode CPC required less energy, and tended to cause less blanching, and deeper ciliary body

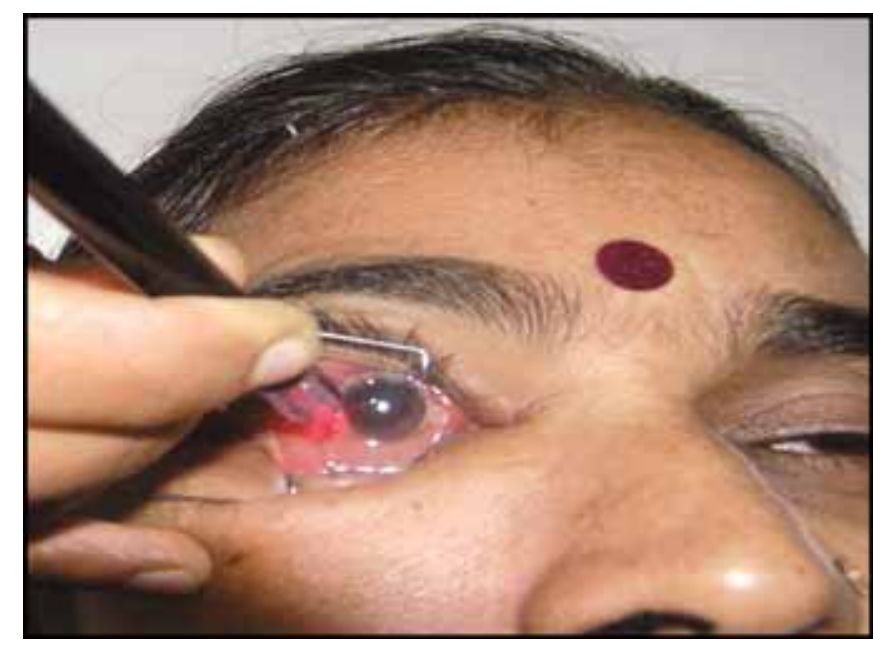

Fig. 3: DLCP procedure underway

contraction and coagulation. ${ }^{9}$ DLCP has been reported to result in $50^{20}$ to 66 percent $^{24}$ decrease in intraocular pressure (IOP). Success of cyclophotocoagulation procedures has been defined variously as achieving IOPs that range from 5 to $20 \mathrm{mmHg}$, or 7 to $21 \mathrm{mmHg}$, that are less than 21 or $22 \mathrm{mmHg}$, and/or a reduction in IOP of from 20 to 30 percent. Most studies allow the postoperative use of medications to achieve this definition of success. The success rate has been reported to vary from 48-89 percent. $^{14-24,31}$ There is so much variation for the fact the treatment protocols are different in different studies as also the definitions of success criteria. In the authors' experience, ${ }^{36}$ diode $\mathrm{CPC}$ with a titrated energy protocol resulted in lower energy requirement in Asian Indian eyes compared to that reported in literature, and different energy levels for different diseases (Table 1). The mean total energy delivered per eye was $87.80 \pm$ 31.8 J, (Range 105.4 $\pm 36.8 \mathrm{~J}$ in neovascular glaucoma (NVG) to $61.5 \pm 8.8 \mathrm{~J}$ in uveitic glaucoma $(\mathrm{p}=0.134))$. Mean pre-treatment IOP was $36.4 \pm 10.7 \mathrm{~mm} \mathrm{Hg}$, which reduced to $19.4 \pm 9.8 \mathrm{~mm} \mathrm{Hg}$

Table 1: Reported outcomes in studies using diode laser cyclophotocoagulation

\begin{tabular}{|c|c|c|c|c|}
\hline & Bloom et al ${ }^{16}$ & Gupta and Aggarwal ${ }^{20}$ & Murphy et al ${ }^{19}$ & Kaushik et al ${ }^{36}$ \\
\hline No. of eyes & 210 & 54 & 263 & 66 \\
\hline Mean pre-IOP (mm Hg) & $34.1 \pm 13.1$ & $44.7 \pm 7.3$ & 40.7(SD 13.7) & $36.5 \pm 12.2$ \\
\hline Energy (J) & 90 & $120-160$ & 155.2 & $80-92$ \\
\hline Applications & $20-40$ & variable & variable & $20-22$ \\
\hline Success & $66 \%$ & $92 \%$ & $89 \%$ & $86.4 \%$ \\
\hline Retreat & $49 \%$ & $42 \%$ & $34.2 \%$ & $16.6 \%$ \\
\hline Treatments per eye & 1.75 & 1.88 & 1.5 & 1.16 \\
\hline Percentage decrease in IOP & - & $66 \%$ & $52.6 \%$ & $67.1 \%$ \\
\hline Complications (Hypotony) & $1 \%$ & Not reported & $9.5 \%$ & $6.06 \%$ \\
\hline
\end{tabular}


( $\mathrm{p}<0.001$ ) at one week, and $15.6 \pm 6.6 \mathrm{~mm} \mathrm{Hg}$ at one-year. At one year, 58 of 66 patients had IOP $<22.0 \mathrm{~mm} \mathrm{Hg(response} \mathrm{rate-}$ $87.8 \%$ ), and 6 patients had hypotony (success rate $78.8 \%$ ). The uveitic glaucoma group had 100 percent success rate and NVG group required maximum re-treatments.

The cyclodiode efficacy index defines the sensitivity of the IOP to cyclodiode therapy. It is determined as the ratio of the response rate (expressed as a decimal) to the mean number of treatment sessions. Thus, a cyclodiode efficacy index of 1.0 would indicate that all the eyes in an evaluated group achieved a satisfactory IOP response following a single treatment episode. Multiple factors have been reported to influence on the success rate of cyclodiode photocoagulation. Gupta and Aggarwal ${ }^{20}$ and Schlote et $\mathrm{al}^{15}$ reported lower age to have adverse effect on the success of surgery (55\% for patients younger than the age of 50 years to 83 percent for patients older than the age of 50 year). Murphy ${ }^{19}$ et al correlated male sex with treatment failure as also the lower mean energy per treatment on univariate analysis, but not on multivariate analysis.

The success rate has been reported to vary with diagnosis as well. Lai et $\mathrm{al}^{31}$ reported the use of TSCPC in 14 eyes with PACG and achieved a success of 85.7 percent. Nabilli and Kirkness $^{26}$ reported success rate of 60 percent in eyes with neovascular glaucoma. Shah et $\mathrm{al}^{29}$ reported a large series of 28 eyes of post PKP glaucoma with a success rate of 79 percent. Schlote et $\mathrm{al}^{28}$ in their series of 18 uveitic eyes reported success rate of 72.2 percent. Success results have been variable for various kinds of refractory glaucoma with poor results in aphakic, childhood and post traumatic glaucomas.

\section{LIMITATION}

The predictability of the procedure is limited by the inability to visualize target tissue. In lieu of direct visualization, transillumination may be used to identify the location of the ciliary body, especially in eyes with abnormal anatomy or enlarged eyes (congenital glaucoma). An ocular transilluminator is placed against the posterior globe and directed towards the ciliary sulcus. In a darkened room, the diffuse illumination will demarcate the ciliary body, which can be marked externally.

\section{COMPLICATION}

Complications seen with all modes of cyclodestruction include pain, intraocular hemorrhage, prolonged ocular inflammation, hypotony, phthisis bulbi $(1.9 \%)^{15}$ visual loss, postoperative pain, and the need for retreatment.

The hypotony rate reported in other studies has been highly variable, ranging from 0 to 18 percent. ${ }^{16,23,24}$ Potential complications of transscleral diode CPC include conjunctival surface burns that heals quickly.

Another potential complication is intraocular disruption ("pop”), which is characterized as an intraocular uveal micro- explosion and represents boiling of tissue water. Postoperative iridocyclitis is more severe with an increased number of pops observed. Malignant glaucoma has been reported in one case series following diode $\mathrm{CPC}^{5}$ Atonic pupil has also been reported in $28^{26}$ to 50 percent $^{31}$ following the laser treatment. There is high risk of graft failure in patients undergoing Diode laser CPC. Shah et al reported 16 percent graft opacification ${ }^{29}$ after the procedure in post-keratoplasty eyes.

\section{CONCLUSIONS}

Cyclophotocoagulation is indicated for patients with refractory glaucoma who have failed trabeculectomy or tube shunt procedures, patients with minimal useful vision and elevated IOP, patients who have no visual potential and need pain relief, and patients with complicated glaucoma and conjunctival scarring from previous surgery. It is also useful in emergent situations, such as the acute onset of neovascular glaucoma.

Recent evidence shows that semiconductor diode systems appear to possess the best combination of effectiveness, portability, expense, ease of use at this time and predictability of the laser and tissue response along with the currently available cyclophotocoagulation techniques available. ${ }^{25}$ Unlike endoscopic CPC, transscleral treatment can usually be performed in an office setting. However, visualizing the treatment target tissue directly is impossible with transscleral treatment and can potentially cause more collateral tissue damage. ${ }^{37}$

\section{REFERENCES}

1. Vogt A. Versuche zur intraokularen druckherabsetzung mittelst diathermieschädigung des corpus ciliare (Zyklodiathermiestiche lung). Klin Monatsbl Augenheilkd 1936;97:672-3.

2. Beitti G. Surgical intervention on the ciliary body; new trends for the relief of glaucoma. JAMA 1950;142:889-97.

3. De Roetth A Jr. Cryosurgery for the treatment of advanced chronic simple glaucoma. Am J Ophthalmol 1968;66:1034-41.

4. Benson MT, Nelson ME. Cyclocryotherapy: Areview of cases over 10 year period. Br J Ophthalmol 1990;74:103-5.

5. Coleman DJ, Lizzi FL, Driller J, et al. Therapeutic ultrasound in the treatment of glaucoma. I. Experimental model. Ophthalmology 1985;92:339-46.

6. Coleman DJ, Lizzi FL, Driller J, et al. Therapeutic ultrasound in the treatment of glaucoma. II. Clinical applications. Ophthalmology 1985;92:347-53.

7. Beckman H, Kinoshita A, Rota AN, Sugar HS. Transscleral ruby laser irradiation of the ciliary body in the treatment of intractable glaucoma. Trans Am Acad Ophthalmol Otolaryngol 1972;76:423-36.

8. Assia EI, Hennis HL, Stewart WC, et al. A comparison of neodymium:yttrium aluminium garnet and diode laser trans-scleral cyclophotocoagulation and cyclocryotherapy. Invest Ophthalmol Vis Sci 1991;32:2774-8.

9. Brancato R, Leoni G, Trabucchi G, et al. Histopathology of continuous wave neodymium:yttrium aluminium garnet and diode laser contact laser trans-scleral lesions in rabbit ciliary body. A 
comparative study. Invest Ophthalmol Vis Sci1991;32:158692.

10. Cantor LB, Nicholas DA, Katz J, et al. Neodymium: YAG transcleral cyclophotocoagulation. The role of pigmentation. Invest Ophthalmol Vis Sci 1989;30:1834-7.

11. Fankhauser F, van der Zypen E, Kwasniewska S, et al. Transcleral cyclophotocoagulation using a neodymium:YAG laser. Ophthalmic Surg 1986;17:94-100.

12. Youn J, Cox TA, Herndon LW, et al. A clinical comparison of transscleral cyclophotocoagulation with neodymium:YAG and semiconductor diode lasers. Am J Ophthalmol 1998;126:640-7.

13. Hennis HL, Stewart WC. Semiconductor diode laser trans scleral cyclophotocoagulation in patients with glaucoma..Am J Ophthalmol 1992;113:81-5.

14. Hawkins TA, Stewart WC. One year results of semiconductor transcleral cyclophotocoagulation in patients with glaucoma. Arch Ophthalmol 1993;111:488-91.

15. Schlote T, Derse M, Rassman K, Nicaeus T, Dietz K, Thiel HJ. Efficacy and safety of transcleral diode laser cyclophotcoagulation for advanced glaucoma. J Glaucoma 2001;10:294-301.

16. Bloom PA, Tsai JC, Sharma K, et al. ‘Cyclodiode’ Trans-scleral diode laser cyclophotocoagulation in the treatment of advanced refractory glaucoma. Ophthalmol 1997;104:1508-20.

17. Mistlberger A, Liebmann JM, Tschiderer H, Ritch R, Ruckhofer J, Grabner G. Diode laser transcleral cyclophotocoagulation for refractory gaucoma. J Glaucoma 2001;10:288-93.

18. Kosoko O, Gaasterland DE, Pollack IP, et al. Long-term outcome of initial ciliary ablation with contact diode laser transscleral cyclophotocoagulation for severe glaucoma. Ophthalmology 1996;103:1294-302.

19. Murphy CC, Burnett CAM, Spry PGD, Broadway DC, Diamond JP. A two centre study of the dose response relation for transscleral diode laser cyclophotocoagulation in refractory glaucoma. Br J Ophthalmol 2003;87:1252-7.

20. Gupta V, Aggarwal HC. Contact transscleral diode laser cyclophotocoagulation treatment for refractory glaucomas in Indian population. Indian J Ophthalmol 2000;48:295-300.

21. Chang SH, Chen YC, Li CY, Wu SC. Contact diode laser tansclearal cyclophotocoagulation for refractory glaucoma: comparison of two treatment protocols. Can J Ophthalmol 2004;39:511-6.

22. Noureddin BN, ZEin W, Haddad C, Ma'luf R, Bashshur Z. Diode laser cyclophotocoagulation for refractory glaucoma: a 1 year follow-up of patients using an aggressive protocol. Eye 2006;20:329-35.

23. Walland MJ. Diode laser cyclophotocoagulation: longer term follow up of a standardized treatment protocol. Clin Exp Ophthalmol 2000;28:263-7.

24. Spencer AF, Vernon SA. 'Cyclodiode': results of a standard protocol. Br J Ophthalmol 1999;83:311-6.

25. Pastor SA, Singh K, Lee D, et al. Cyclophotocoagulation. A report by the American Academy of Ophthalmology. Ophthalmology 2001;108:2130-8.

26. Nabilli S, Kirkness CM. Trans-scleral diode laser cyclophotocoagulation in the treatment of diabetic neovascular glaucoma. Eye 2004;18:352-56.
27. Autrata R, Rehurek J. Long-term results of transscleral cyclophotocoagulation in refractory pediatric glaucoma patients. Ophthalmologica 2003;217(6):393-400.

28. Schlote T, Derse M, Zeirhut M. Transscleral diode laser cyclophotocoagulation for the treatment of refractory glaucoma secondary to inflammatory eye diseases. Br J Ophthalmol 2000;84:999-1003.

29. Shah P, Lee GA, Kirwan JK, Bunce C, Bloom PA, Ficker LA, Khaw PT. Cyclodiode photocoagulation for refractory glaucoma after Penetrating Keratoplasty. Ophthalmology 2001;10:198691.

30. Sivagnanavel V, Ortiz-Hurtado A, Williamson TH. Diode laser trans-scleral cyclophotocoagulation in the management of glaucoma in patients with long-term intravitreal silicone oil. Eye 2005;19(3):253-7.

31. Lai JSM, Tham CCY, Chan JCH, Lam DSC. Diode laser transscleral Cyclophotocoagulation in the treatment of chronic angle closure glaucoma: A preliminary study. J Glaucoma 2003;12(4):360-4.

32. Al-Ghamdi S, Al-Obeidan S, Tomey KF, et al. Transscleral neodymium:YAG laser cyclophotocoagulation for endstage glaucoma, refractory glaucoma and painful blind eyes. Ophthalmic Surg 1993;24:526-9.

33. Latina MA, Pate1 S, de Kater AW, et al.Transscleral cyclophotocoagulation using a contact laser probe: a histologic and clinical study in rabbits. Laser Surg Med 1989;9:437-8.

34. Mina B. Pantcheva, Malik Y. Kahook, Joel S Schuman, Robert J Noecker. Comparison of acute structural and transscleral cyclophotocoagulationafter endoscopic cyclophotocoagulation and histopathological changes in human autopsy eyes. Br J Ophthalmol doi:10.1136/bjo.2006.103580

35. Carrillo MC, trope GE, Chipman ML, Buys YM. Repeated use of transscleral cyclophotocoagulation Laser G-Probes. J Glaucoma 2004;13:51-54.

36. Kaushik S, Pandav SS, Jain R, et al. Lower energy levels adequate for effective transcleral diode laser cyclo-photocoagulation in Asian eyes with refractory glaucoma. Eye 2006. In Press.

37. Schuman JS, Noecker RJ, Puliafito CA, et al. Energy levels and probe placementin contact transscleral semiconductor diode laser cyclophotocoagulation in humancadaver eyes. Arch Ophthalmol 1991;109:1534-1538.

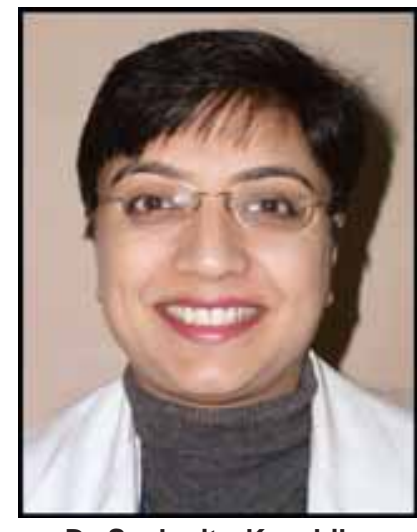

Dr Sushmita Kaushik

(sushmita_kaushik@yahoo.com) 